NASA Technical Memorandum 105933

\title{
Closed Brayton Cycle Power System with a High Temperature Pellet Bed Reactor Heat Source for NEP Applications
}

\author{
Albert J. Juhasz \\ Lewis Research Center \\ Cleveland, Ohio \\ Mohamed S. El-Genk \\ ISNPS \\ University of New Mexico \\ Albuquerque, New Mexico
}

and

William B. Harper, Jr.

Allied Signal Aerospace

Tempe, Arizona

Prepared for the

Tenth Symposium on Space Nuclear Power and Propulsion

Albuquerque, New Mexico, January 10-14, 1993 


\title{
CLOSED BRAYTON CYCLE POWER SYSTEM WITH A HIGH TEMPERATURE PELLET BED REACTOR HEAT SOURCE FOR NEP APPLICATIONS
}

\author{
Albert J. Juhasz \\ NASA LeRC \\ Cleveland, Ohio 44135
}

\author{
Mohamed S. El-Genk \\ ISNPS \\ University of New Mexico \\ Albuquerque, New Mexico 87131 \\ $\underline{\text { Abstract }}$
}

\author{
William B. Harper, Jr. \\ Allied Signal Aerospace \\ Tempe, Arizona 85285-2200
}

\begin{abstract}
Capitalizing on past and future development of high temperature gas reactor (HTGR) technology, a low mass $15 \mathrm{MWe}$ closed gas turbine cycle power system using a pellet bed reactor heating helium working fluid is proposed for Nuclear Electric Propulsion (NEP) applications. Although the design of this directly coupled system architecture, comprising the reactor/power system/space radiator subsystems, is presented in conceptual form, sufficient detail is included to permit an assessment of overall system performance and mass. Furthermore, an attempt is made to show how tailoring of the main subsystem design characteristics can be utilized to achieve synergistic system level advantages that can lead to improved reliability and enhanced system life while reducing the number of parasitic load driven peripheral subsytems.
\end{abstract}

\section{INTRODUCTION}

Development of He gas turbine power systems directly coupled to high temperature gas reactors (HTGR) with exit temperatures in the $2000 \mathrm{~K}$ range will be greatly aided by a developing experience and data base in two areas.

The first of these is the ongoing work on "Modular High Temperature Gas Reactors" (MHTGR) for terrestrial power generation, as discussed in a number of publications ( McDonald, 1992; Schleicher et al, 1992; and Tilliette, 1991). This work, in turn, is based on the pioneering developments on industrial "closed cycle gas turbine" (CCGT) power plants in Switzerland, dating back to 1939, which demonstrated the utilization of fossil fuels, primarily coal, as a heat source for power plants operating in the combined power and heat production mode. With the advent of nuclear reactor technology the plants were modified to permit fueling with either conventional or nuclear sources (Keller and Schmidt, 1966; Bammert, 1966). The main economic attractiveness of these plants stems from their high efficiency, achieved by virtue of their high turbine inlet temperature (up to $1450 \mathrm{~K}$ ) and consequent high cycle temperature ratio, and also the clean inert He gas working fluid which promises reliable operation and less frequent outages over longer service lifetimes than offered by steam power plants.

The second, and even more ambitious, emerging technology with potential impact on space based CCGT development flows from a renewed interest, after a 25 year hiatus, in HTGR research focussed on nuclear thermal propulsion (NTP) for exploration of interplanetary space, including a manned mission to Mars. Although NTP was also the motivation for most of the previous space reactor development efforts, starting with the NERVA-ROVER program of the sixties to the recently disclosed CIS (Commonwealth of Independent States) solid core nuclear thermal reactor concept (Wetch, 1991), derivatives of these concepts can be readily applied to closed cycle systems (Powell, 1992). The reactor modifications required include replacing the hydrogen propellant by the more easily contained helium reactor coolant and cycle working fluid and lowering reactor gas exit temperatures from over $3100 \mathrm{~K}$ to the $2000 \mathrm{~K}$ to $2100 \mathrm{~K}$ range. At the lower gas temperatures reactor operating life can be extended from a few hours to several thousand hours, with at least one year of continuous operation being a reasonable development goal. As an example of progress toward this goal, the CIS concept, using a hydrogen cooled zirconium hydride moderator and ternary carbide fuel material has demonstrated gas exit temperatures of $3100 \mathrm{~K}$ for one hour, and over $2000 \mathrm{~K}$ for $4000 \mathrm{hours}$. In NEP applications such reactor concepts, culminating in the pellet bed reactor (PeBR), when directly coupled to light weight CCGT power systems, can achieve specific impulse, Isp, values in the 3000 to 10,000 sec range, as compared to $925 \mathrm{sec}$ for NTP, and about $450 \mathrm{sec}$ for advanced chemical propulsion systems. Also, the low power system specific mass enables an Earth-Mars trip time of less than a year. 
The purpose of this paper is to present results of a conceptual design study for use in a possible future detailed design. In performing this work, reactor/closed cycle gas turbine/and heat rejection subsystem integration studies were based on a system code (BRMAPS), developed by the author at NASA LeRC. This code has the capability for automatic system optimization based on any of several criteria, such as cycle efficiency, radiator area, or overall system mass. For this study additional constraints were imposed, namely a $430 \mathrm{~K}$ radiator exit gas and an $800 \mathrm{~K}$ reactor inlet temperature, for auxiliary cooling of the shield and the reactor pressure vessel. For comparison, performance parameters for a high efficiency recuperated cycle and a minimum mass simple cycle were also generated. This permitted determination of the overall system mass penalty incurred by tailoring the cycle to the above constraints.

\section{POWER SYSTEM ARCHITECTURE AND MAJOR SUBSYSTEMS}

\section{Conceptual Design Considerations}

The conceptual schematic for a $15 \mathrm{MWe}$ three independent loop gas turbine space power system, with 5 MWe generated in each loop, is shown in figure 1, with state points described in table 1 . Since the three loops are heated by the same PeBR (pellet bed reactor), (El-Genk et al., 1992) of nominally $50 \mathrm{MWt}$ power, each of the heat sources shown in the three loops represent a 120 degree sector of the shadow shielded reactor. The system can be designed so that, by increasing the working fluid inventory in the loops, any two of the three loops can supply the full power output if one loop fails.

Before discussing the main subsystems (reactor, compressor-turbine-alternator unit, and radiator) in further detail, a few remarks concerning the design considerations leading to the selection of the $2000 \mathrm{~K}$ turbine inlet temperature for the conceptual power system are in order.

For optimum performance the highest turbine inlet temperature compatible with available materials technology is desired. With the He cooled PeBR design utilizing $\mathrm{ZrC}$ coated fuel pellets enclosing "Triso" (UC-ZrC) micro-spheres in a graphite matrix, capable of over $2200 \mathrm{~K}$ operating gas temperature, attention was focussed on material temperatures encountered at various gas temperatures by limiting Closed Brayton Cycle (CBC) components. Drawing on the existing aircraft gas turbine materials data base, figure 2 was prepared by including a modest temperature extrapolation to account for expected advances in technology over the next two decades, and also considering the less severe operating environment of an inert gas space power system, as contrasted to the oxidizing, vitiated air atmosphere encountered by stationary power and aircraft gas turbines.

An examination of the $\mathrm{CBC}$ materials technology picture presented in figure 2 reveals that the highest temperatures would be encountered on the hot side of the heat source heat exchanger, since for a given turbine inlet gas temperature the hot side must be at an even higher temperature for heat transfer to take place. Fortunately, for the directly heated PeBR/CBC system a heat exchanger is not required, thus eliminating the most severe obstacle to high turbine inlet temperature. The next lower curve of figure 2, shows that the temperature limiting components for directly heated gas turbines are the turbine stators, which will reach turbine gas temperature in the uncooled case, as assumed here. However, composites utilizing graphite fibers in a carbon matrix should be capable of operating in a $2000 \mathrm{~K}$ inert gas environment, while maintaining or even increasing their tensile strength at high temperatures. Hence $2000 \mathrm{~K}$ was chosen as the turbine inlet temperature for all cycle computations. It should be noted, that the turbine rotor blade material temperature will be considerably below the turbine inlet gas temperature, since relative motion between the gas and blade prevents attainment of stagnation temperatures. Nevertheless a graphite-carbon composite is the material of choice for the turbine stages. Again, the excellent creep strength and low density of graphite carbon composites should permit operation at high turbine speeds necessary with the low molecular weight He fluid. The lowest material temperatures are shown to be encountered in the recuperator, if one is used, with either composites or alumina ceramics being candidate materials.

Highlights of the main subsystems will be discussed in the following sections. 


\section{Pellet Bed Reactor and Shield}

The PeBR heat source with its instrument rated shadow shield, directly coupled to each of the loops, actually represents 120 degree sectors of the same reactor (figure 1). Since reactor safety features and the fuel pellet design are treated in depth (El-Genk et al., 1992), this discussion is devoted to the thermal-hydraulics of the reactor, as it affects integration with the overall system.

An elevation view of the reactor-shield combination and a transverse section of a 120 degree sector are shown in figure $3 \mathrm{a}$ and $3 \mathrm{~b}$, respectively. The instrument rated shield with a 10 degree half cone angle is designed to limit the payload gamma radiation dose to 1.0 megarads and a neutron fluence of 10 exp $13 \mathrm{nvt}$ at a 125 meter separation distance. Since the LiH neutron absorption section of the shield needs to be maintained between $600 \mathrm{~K}$ and $680 \mathrm{~K}$ to prevent $\mathrm{LiH}$ dissociation, the shield is cooled by He gas flow returning from the radiator at about $430 \mathrm{~K}$ before proceeding to the compressor at $450 \mathrm{~K}$. At the 3.6 design pressure ratio, the compressor exit (reactor inlet) gas temperature of $800 \mathrm{~K}$ is routed the outer annulus between the reactor core and the stainless steel pressure vessel wall and the top and bottom $\mathrm{BeC}$ axial reflectors for cooling. The helium flows radially inward through the cold frit structure into the PeBR core while being heated by the fission energy generated in the fuel pellets. The radial reflector and reactor vessel wall are also cooled by an auxiliary potassium heat pipe radiator for removal of decay heat after reactor and power system shutdown. The core is surrounded by segmented boron carbide/beryllium carbide control drums (fig. 3b) integrated into the radial reflector structure.

Owing to its large flow cross sectional area the core pressure loss is as low as 1 percent of system pressure, assumed at $1 \mathrm{MPa}$ here. Due to low Reynolds Numbers (based on fuel pellet diameter) and cross communication of flow between passages, laminar flow instability (Turney et al.,1966; Reshotko, 1967; Black ,1993) problems are avoided.

\section{Turbomachinery and Alternator}

The technology level developed for terrestrial open cycle gas turbines (Gas Turbine Handbook, 1991) shows that power densities as high as $10 \mathrm{~kW} / \mathrm{kg}$ can be achieved at the multi-megawatt power levels of interest. This technology is also applicable to space based He machines, except for the fact that for He the turbomachinery, diameters and blade passage heights would only be about 65 percent of terrestrial open cycle machine dimensions. The smaller diameter requirement, $0.7 \mathrm{~m}$ for this application, coupled with the use of light weight composite blading should permit turbine speeds in the 24,000 to $30,000 \mathrm{rpm}$ range, needed for high machine efficiencies with the He working fluid. For the conceptual power system discussed here respective isentropic compressor and turbine efficiencies of $86 \%$ and $93 \%$ were computed for the above speed range.

Determination of operating pressure, rotational speed, and desired turbomachinery efficiency, as well as matching to desired alternator characteristics presents another challenging optimization problem. This is because high rotational speeds (Kofskey et al., 1964) are required for maximum compressor and turbine efficiency, while the alternator needs to be driven at a synchronous speed, which is a function of the number of generator pole pairs and the frequency of the alternating current being generated. For the frequencies ( 50 to $60 \mathrm{hz}$ ), traditionally generated for terrestrial users, synchronous speeds in the 1000 to $3600 \mathrm{rpm}$ range are required. If a frequency greater than $60 \mathrm{hz}$ can be used, then a speed reducer or a twin turbine spool arrangement may not be necessary. For example, at a frequency of $400 \mathrm{hz}$, a direct turbine drive speed at $24000 \mathrm{rpm}$ is compatible with the synchronous speed requirement for a two pole alternator, while a six pole alternator driven at he same speed would generate current at $1.2 \mathrm{khz}$. It should also be noted that at these higher frequencies there is an additional benefit in that the specific weight of magnetic components is reduced by more than an order of magnitude (Schwarze, 1984). These magnetics would include transformers which may be necessary for changing the generator terminal voltage (up to $10 \mathrm{kV}$ ) to levels tailored to various subsystem requirements, i.e. thrusters, peripheral drives and actuators, and magnetic bearings. The alternator and power conditioning components are cooled by separate radiators using water heat pipes. 


\section{Radiator and Heat Rejection Subsystem}

A conceptual flat plate radiator, shared by the three gas turbine power loops, is shown in figure 4 . This heat rejection load sharing is made possible by a radiator duct which carries the turbine exhaust stream in three separate adjacent bifurcated radiator ducts which communicate thermally with the $0.05 \mathrm{~m}$ dia. $1.5 \mathrm{~m}$ long heat pipe evaporators by combined convective- conductive heat transfer. The computed He gas and heat pipe evaporator wall temperature profiles as the flow proceeds along the radiator duct, are shown in figure 5. Note that these profiles were computed under the assumption of equal heat pipe condenser length, i.e. constant incremental radiator area with incremental duct length. To accommodate the over $800 \mathrm{~K}$ temperature drop for the selected cycle (see also table 2) the radiator is divided into five temperature regions, or zones, each of which is bounded by the temperatures corresponding to the heat pipe operating limits associated with the indicated working fluids: sodium, potassium, cesium, sulfur-iodine (in lieu of mercury), and water.

The radiator areas shown in table 2 for the three cycle configurations were based on the computed heat rejection load requirement at unity view factor, computed heat pipe condenser surface temperatures, surface emissivity of 0.85 , and a fin efficiency of 0.9 . The relatively high value of fin efficiency was based on the work on high conductivity graphite-carbon composite radiator elements being conducted under contract with NASA Lewis on advanced radiator concepts (Juhasz, 1991). Axial conductivities for graphite composite samples in excess of $600 \mathrm{w} / \mathrm{m}-\mathrm{K}$ were demonstrated under this effort.

In addition to meeting the area requirement for heat rejection by radiative heat transfer, the radiator design must also guarantee that the total heat to be rejected to the space sink can be absorbed by the heat pipe evaporator segments in each of the five radiator zones. This means that the evaporator heat flux and heat transport requirements must be lower than the values set by the individual heat pipe operating limits. With the $\mathrm{Na}, \mathrm{K}$, and $\mathrm{Cs}$ heat pipes absorbing most of the cycle reject heat from the He stream, as indicated by the profiles of figure 5, higher evaporator heat fluxes are required for these pipes than for those in the downstream regions. Fortunately, these higher heat load requirements are compatible with demonstrated performance of the three types of liquid metal heat pipes considered. However, for the cooler downstream radiator zones, below $650 \mathrm{~K}$ evaporator surface temperature, it may be necessary to provide for increased evaporator surface area, in addition to that provided by the proposed flat plate conceptual design. This contingency could be provided for, at a small decrease in view factor (to near 0.95), by adding heat pipe panels perpendicular to the existing radiating surfaces in the downstream zones. These panels would use L shaped heat pipes with evaporators in thermal contact with the top or bottom surfaces of the ducts. Note that, by virtue of separately carrying three flow streams, the ducts do provide for redundancy against micrometeoroid punctures of the heat rejection loop. But since there is no requirement for the ducts to radiate to space, they can be provided with sufficient bumper shield protection to virtually eliminate the probability of puncture. In contrast, the radiator panels in each zone, consisting of large numbers of finned heat pipe condensers (10 $\mathrm{m}$ long), which are vulnerable to micrometeoroid and space debris damage, cannot be protected by shielding, since that would impede their heat rejection capability. To ensure a 95 percent survivability these panels are provided with 10 percent excess heat pipe redundancy. Note that, by achieving direct cooling of the He working fluid, this two sided flat plate heat pipe radiator concept eliminates the need for a separate heat rejection loop with gas-liquid heat exchangers and parasitic power driven pumps.

\section{Power System Study Results and Observations}

An examination of the system parameter values for the three options shown in table 2, reveals the penalty in system performance and mass for the recuperated and the selected cycle configurations, as compared to a "minimum mass" cycle. But it should also be noted that only the selected cycle meets the $430 \mathrm{~K}$ radiator exit temperature constraint to provide for shield cooling and the $800 \mathrm{~K}$ reactor inlet temperature needed for reactor pressure vessel cooling. Although power system mass for the selected conceptual cycle is shown to increase from 43.6 to 49.3 metric tons, the system specific mass only increased from 2.9 to $3.3 \mathrm{~kg} / \mathrm{kWe}$, a value well within the $5 \mathrm{~kg} / \mathrm{kWe}$ goal required for an Earth-Mars transit time less than 400 days.

Although not shown in the system schematic (figure 1), addition of pressurized working fluid reservoirs, 
valved to the compressor inlet ducts, would permit increasing the turbine shaft power in direct proportion to the increase in fluid mass flow rate or pressure level. Assuming that the reactor heat input and the alternator magnetic field strength can also be adjusted, in the event of complete loss of power in any one of the loops this feature would permit power output to remain at design value by increasing the power output in the remaining two loops.

\section{CONCLUDING REMARKS}

In spite of their challenging radiator design requirements, with sufficient development, directly heated high temperature closed cycle gas turbine power systems, using inert gas working fluids, do offer several advantages for space and planetary surface power generation.

Among these are: Long term reliability, due to absence of working fluid induced contamination and corrosion; Performance unaffected by the local gravity field; and Capability of regulating output power entirely by working fluid inventory control.

Availability of a huge terrestrial technology data base, coupled with the non-hazardous inert gas working fluids should permit component development for space power applications at lower cost than for other candidate systems requiring testing with liquid metals at high temperatures.

High temperature CBC technology generated in the development of NEP power systems would also be applicable to lunar or Martian surface power plants of the future.

\section{Acknowledgments}

This work was carried out at the NASA Lewis Research Center with Support from the University of New Mexico and the Allied Signal Aerospace Co.

\section{References}

Bammert, K.: "Remarks to the Problem of Optimum Design of Nuclear Gas Turbine Power Plants", Atomkernenergie, January/February 1966.

Black, D. L. : "Laminar Flow Instability in Nuclear Rockets", 10th Symposium on Space Nuclear Power and Propulsion, Albuquerque, NM, Jan 11-14, 1993.

El-Genk, M.S.; Morley, N.J.; and Juhasz, A.J.: "Pellet Bed Reactor Concept for Nuclear Electric Propulsion" 10th Symposium on Space Nuclear Power and Propulsion", Albuquerque, NM, Jan 11-14, 1993.

Gas Turbine World: "The 1991 Handbook" Volume 13, Pequot Publishing, Fairfield, CT, 1991.

Juhasz, Albert J.: "An Overview of The Lewis Research Center Thermal Management Program", Conference on Advanced Space Exploration Initiative Technologies, cosponsored by AIAA, NASA, and OAI, Cleveland, Ohio, September 4-6, 1991.

Keller, C. and Schmidt, D.: "Industrial Closed Cycle Gas turbines for Conventional and Nuclear Fuel", ASME Paper 67-GT-10, presented at the Gas Turbine Conference and Products Show, Houston, Texas, 3/5-9, 1967.

Kofskey, M. G., and Glassman, A. G.:"Turbomachinery Characteristics of Brayton Cycle Space Power Generation Systems" presented at the Gas Turbine Conference and Products Show, Houston, Texas, March 1-5, 1964.

McDonald, Colin F. : "Gas Cooled Reactor Opportunities in the 21st Century", 27th IECEC Proceedings, Vol. 4, San Diego, Ca., August 3-7, 1992. 
Powell, J. R. : Personal Communication, Oct. 1992

Reshotko, Eli: "An Analysis of the Laminar Flow Instability Problem in Gas-Cooled Nuclear Reactor Passages", AIAA Journal, Vol. 5. No. 9 (Sept., 1967), pp. 1606-1615.

Schleicher, R. W., Kapich, D. D., and Etzel, K. T.: "Modular Gas Turbine Power Plant", 27th IECEC Proceedings, Vol. 4, San Diego, Ca., August 3-7, 1992.

Schwarze, Gene E.: Development of High Frequency Low Weight Power Magnetics for Aerospace Power Systems" 19th IECEC, San Francisco, Ca. August 19-24, 1984. NASA TM 83656.

Tilliette, Z. P.: " A Contribution to the HTGR Energy Conversion Issue", 26th IECEC Proceedings, Vol. 5, Boston, Ma., August 1991.

Turney, G. E., Smith, J. M., and Juhasz, A. J.; "Steady State Investigation of Laminar-Flow Instability Problem Resulting from Relatively Large Increases in Temperature of Normal Hydrogen Gas Flowing in Small Diameter Tubes", NASA TND-3347, May 1966.

Wetch, J. R. :"Development of Nuclear Rocket Engines in the USSR", AIAA/NASA/OAI Conference on Advanced SEI Technologies, Cleveland, Ohio, Sept. 4-6, 1991.

TABLE 1: Gas Turbine Power Loop State Points

\begin{tabular}{||c|c|c|}
\hline State Point & $\begin{array}{c}\text { Temperature } \\
(\mathrm{K})\end{array}$ & $\begin{array}{c}\text { Pressure } \\
(\mathrm{MPa})\end{array}$ \\
\hline \hline 1 & 2000 & 0.99 \\
\hline 2 & 1284 & 0.29 \\
\hline 3 & 1278 & 0.29 \\
\hline 4 & 430 & 0.28 \\
\hline 5 & 433 & 0.28 \\
\hline 6 & 450 & 0.277 \\
\hline 7 & 800 & 1.00 \\
\hline 8 & 800 & 1.00 \\
\hline
\end{tabular}


TABLE 2: Power System Characteristics and Performance

\begin{tabular}{||l|c|c|c||}
\hline \multicolumn{1}{|c|}{ Gas Turbine Cycle Parameters } & $\begin{array}{c}\text { Recuperated } \\
\text { Cycle }\end{array}$ & $\begin{array}{c}\text { Minimum } \\
\text { Mass } \\
\text { Cycle }\end{array}$ & $\begin{array}{c}\text { Selected } \\
\text { Cycle }\end{array}$ \\
\hline \hline Turbine Inlet Temperature - K & 2000. & 2000. & 2000. \\
\hline Cycle Temperature Ratio & 4.44 & 3.3 & 4.44 \\
\hline Compressor Inlet Temperature - K & $\mathbf{4 5 0 .}$ & 606. & $\mathbf{4 5 0 .}$ \\
\hline Compressor Pressure Ratio & 3.6 & 4.1 & 3.6 \\
\hline Compressor Exit Temperature - K & $\mathbf{8 0 0 .}$ & 1135. & $\mathbf{8 0 0 .}$ \\
\hline Reactor Inlet Temperature - K & 1279. & 1135. & $\mathbf{8 0 0 .}$ \\
\hline Loop Helium Flowrate - kg/sec & 2.87 & 4.17 & 2.75 \\
\hline Cycle Pressure Loss Parameter & 0.90 & 0.95 & 0.95 \\
\hline Recuperator Effectiveness & 0.95 & 0.00 & 0.00 \\
\hline Cycle Thermal Efficiency - $\%$ & 45.1 & 26.7 & 29.1 \\
\hline Cycle Heat Rejected - MWt & 18.3 & 40.3 & 35.6 \\
\hline Radiator Duct Inlet Temperature-K & 826. & 1226. & 1279. \\
\hline Radiator Duct Exit Temperature- K & $\mathbf{4 3 0 .}$ & 586. & $\mathbf{4 3 0 .}$ \\
\hline Effective Radiator Temperature -K & 550. & 759. & 645. \\
\hline Space Sink Temperature - K & 225. & 225. & 225. \\
\hline Main Radiator Area - sq. m. & 4795. & 3104. & 5300. \\
\hline System Specific Power - W/kg & 267.2 & 344.3 & 304.1 \\
\hline System Specific Mass - kg/kW & 3.74 & 2.9 & 3.29 \\
\hline Total System Mass - Tonnes & 56.74 & 43.56 & 49.30 \\
\hline
\end{tabular}




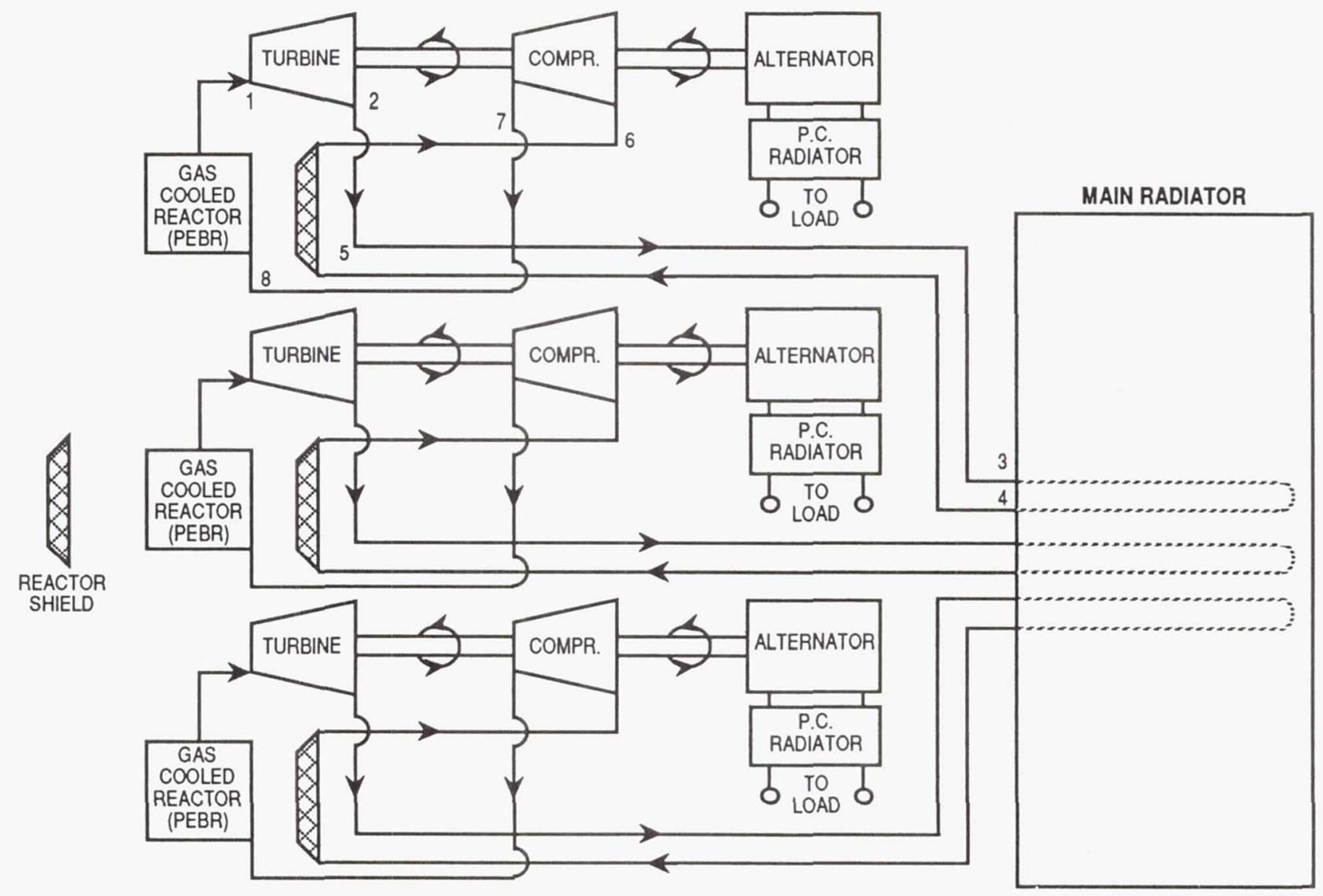

Figure 1: $15 \mathrm{MWe}$ PeBr/CBC Gas Turbine Power System

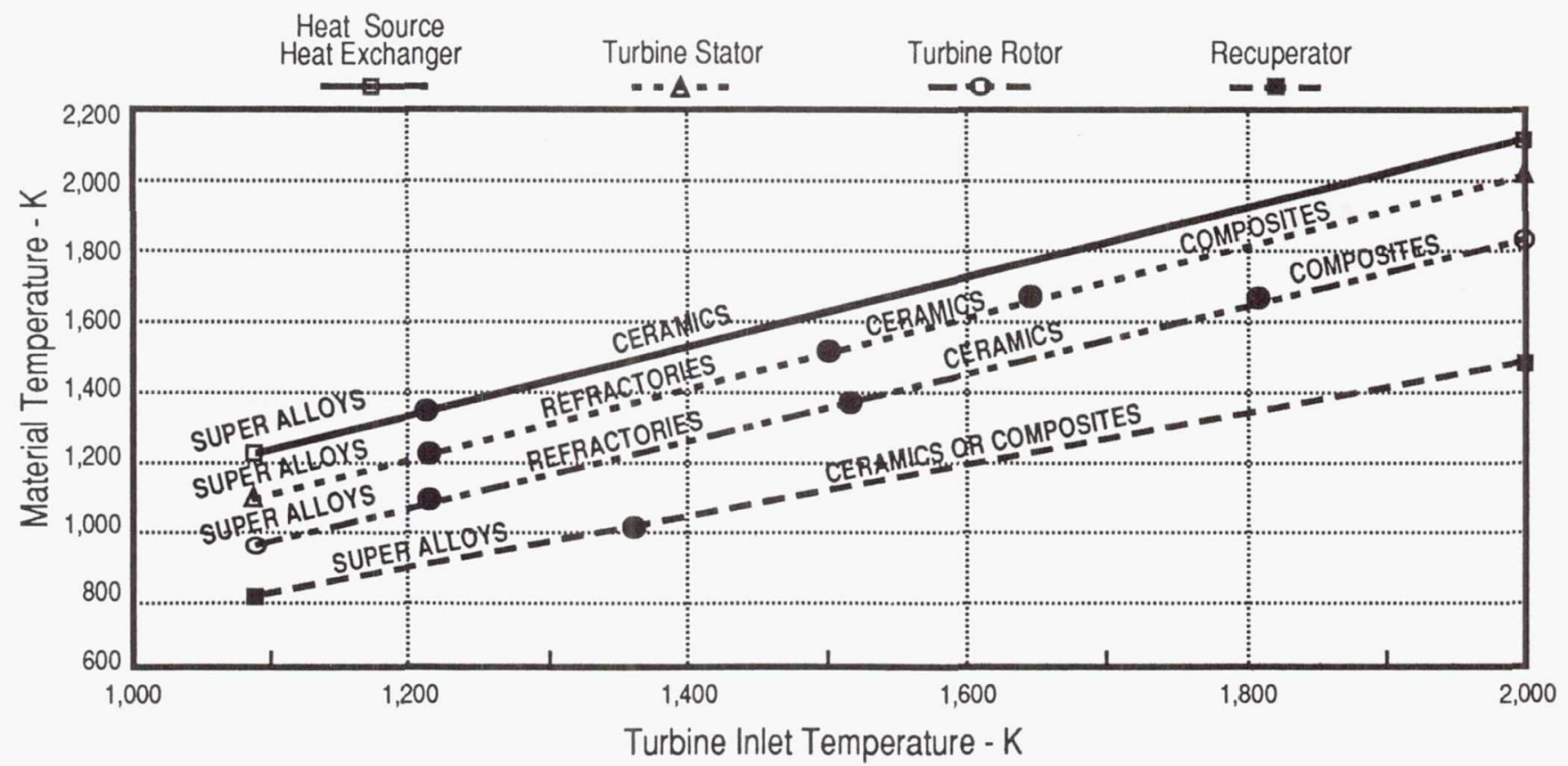

Figure 2: Gas Turbine Materials Technology 


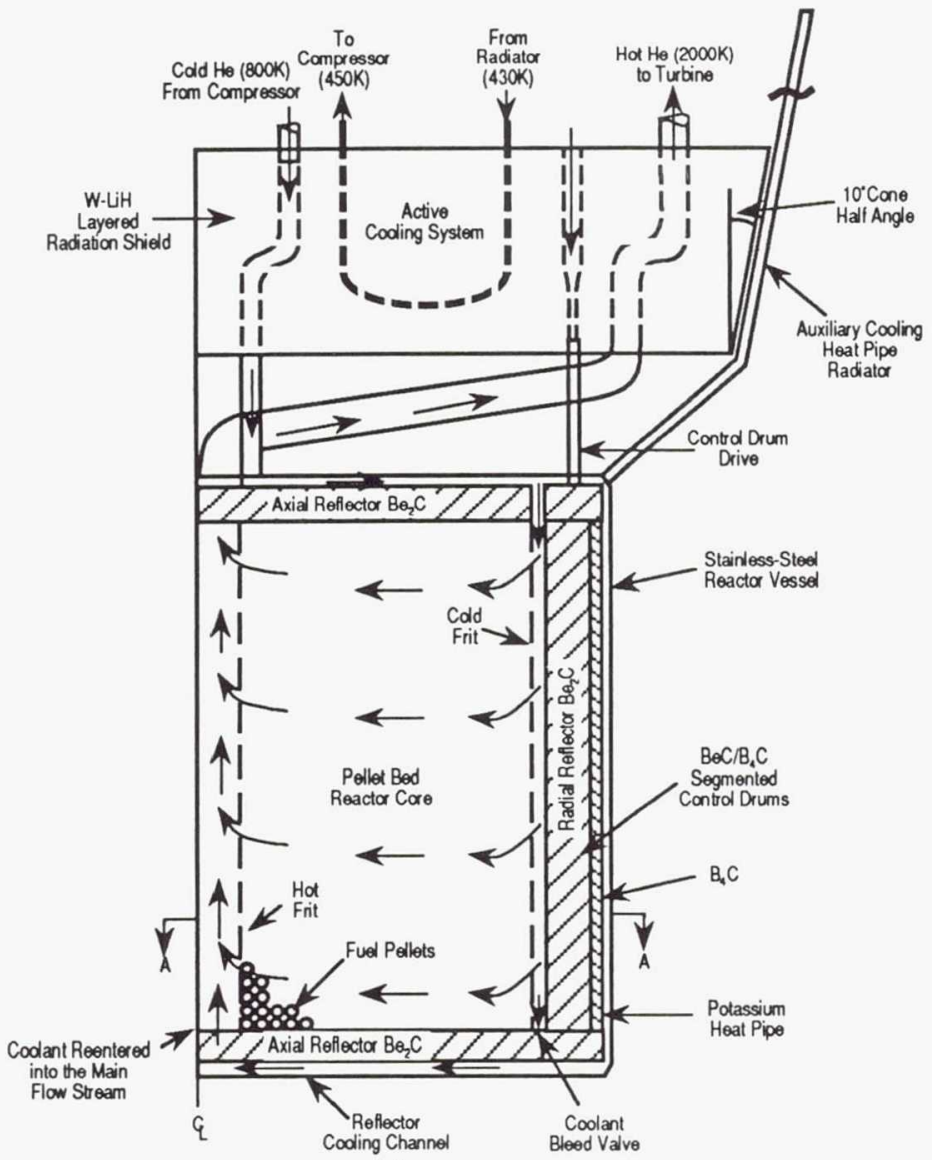

(a)

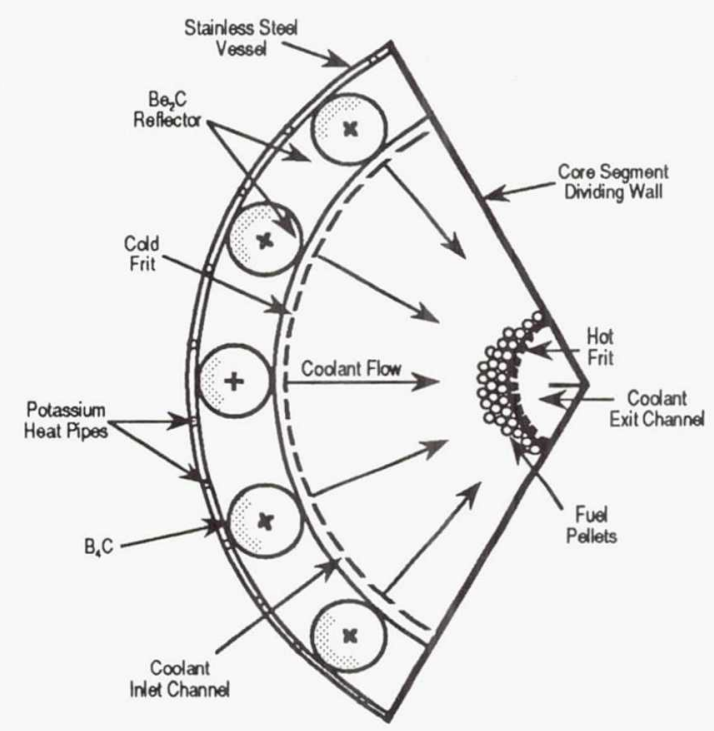

Figure 3: Pellet Bed Reactor: (a) Elevation View, (b) Planar Section

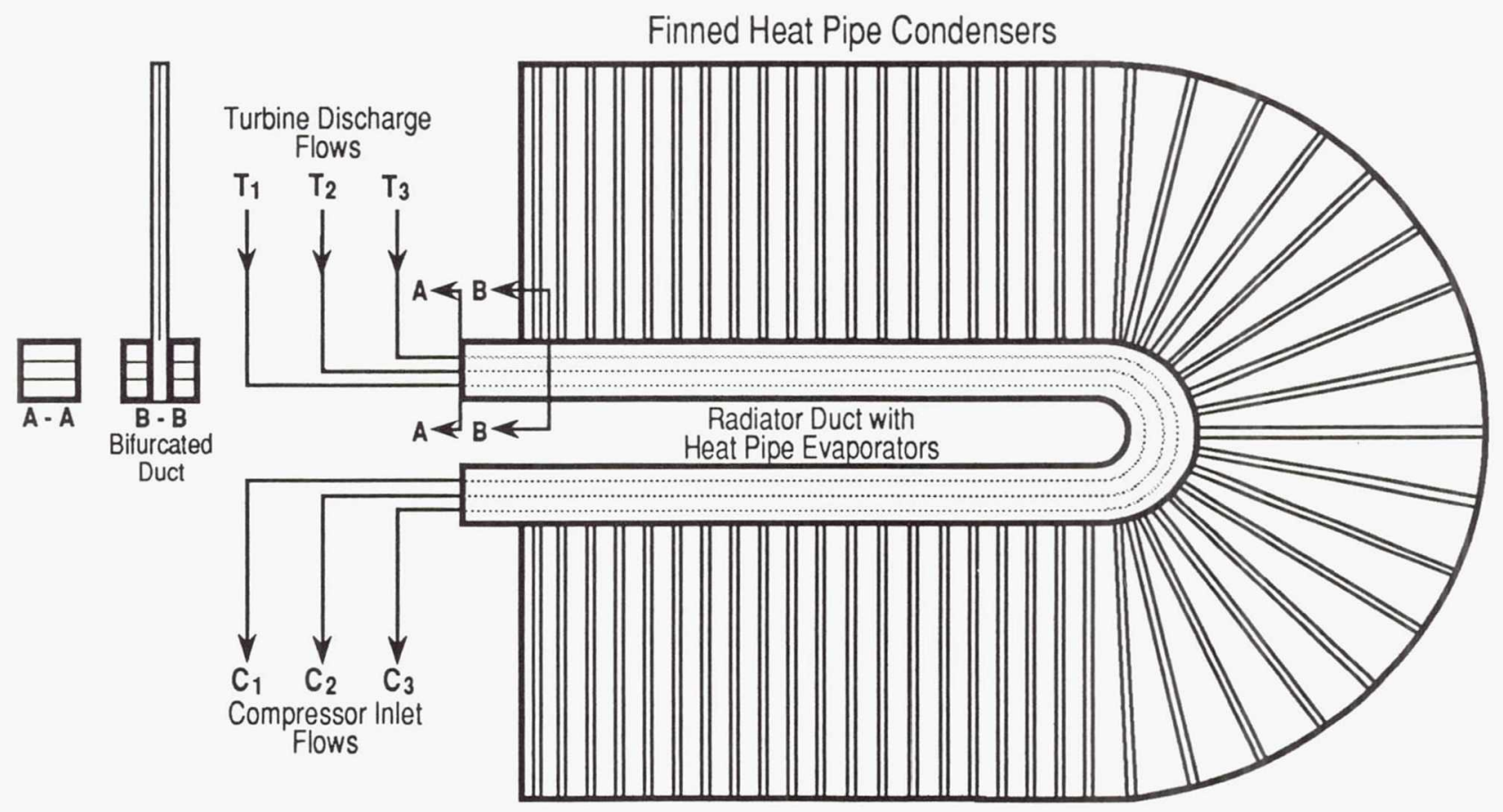

Figure 4: Flat Plate Heat Pipe Radiator for PeBR/CBC Power System 


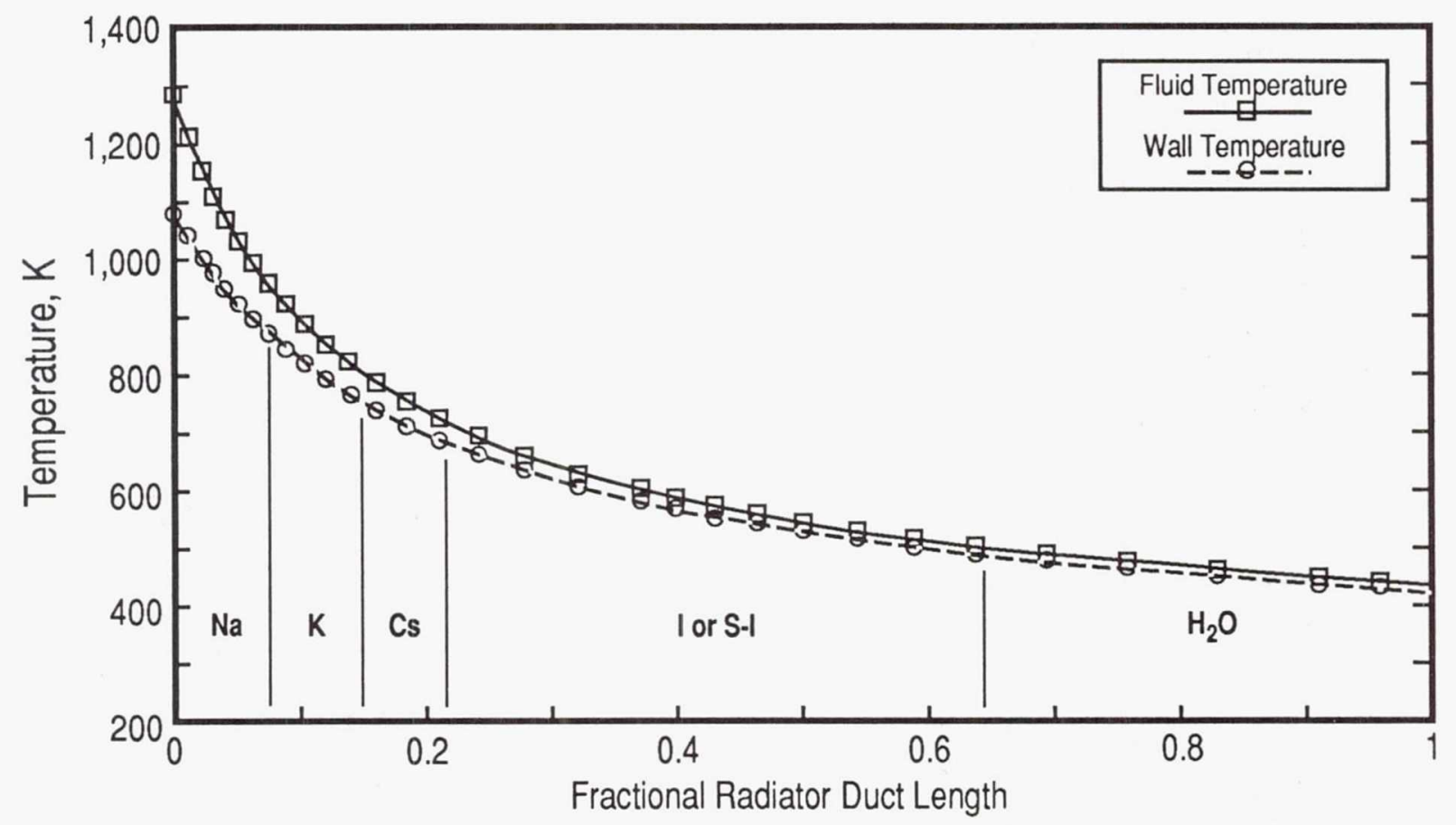

Figure 5: Heat Pipe Radiator Temperature Profiles

(Letters between lines designate HP working fluids) 
Public reporting burden for this collection of information is estimated to average 1 hour per response, including the time for reviewing instructions, searching existing data sources, gathering and maintaining the data needed, and completing and reviewing the collection of information. Send comments regarding this burden estimate or any other aspect of this collection of information, including suggestions for reducing this burden, to Washington Headquarters Services, Directorate for information Operations and Reports, 1215 Jefferson Davis Highway, Suite 1204, Arlington, VA 22202-4302, and to the Office of Management and Budget, Paperwork Reduction Project (0704-0188), Washington, DC 20503.

\begin{tabular}{|l|c|r|}
\hline 1. AGENCY USE ONLY (Leave blank) & $\begin{array}{c}\text { 2. REPORT DATE } \\
\text { October } 1992\end{array}$ & $\begin{array}{r}\text { 3. REPORT TYPE AND DATES COVERED } \\
\text { Technical Memorandum }\end{array}$ \\
\hline
\end{tabular}

\section{TITLE AND SUBTITLE} 5. FUNDING NUMBERS

Closed Brayton Cycle Power System with a High Temperature Pellet Bed Reactor Heat Source for NEP Applications

\section{AUTHOR(S)}

Albert J. Juhasz, Mohamed S. El-Genk, and William B. Harper, Jr.

WU-590-13-11

7. PERFORMING ORGANIZATION NAME(S) AND ADDRESS(ES

8. PERFORMING ORGANIZATION REPORT NUMBER

National Aeronautics and Space Administration

Lewis Research Center

E-7446

Cleveland, Ohio 44135-3191

\section{SPONSORING/MONITORING AGENCY NAMES(S) AND ADDRESS(ES)}

10. SPONSORING/MONITORING AGENCY REPORT NUMBER

National Aeronautics and Space Administration

Washington, D.C. 20546-0001

NASA TM-105933

\section{SUPPLEMENTARY NOTES}

Prepared for the Tenth Symposium on Space Nuclear Power and Propulsion, Albuquerque, New Mexico, January 10-14, 1993. Albert J. Juhasz, NASA Lewis Research Center, Cleveland, Ohio; Mohamed S. El-Genk, University of New Mexico, Albuquerque, New Mexico, and William B. Harper, Jr., Allied Signal Aerospace.

12a. DISTRIBUTION/AVAILABILITY STATEMENT 12b. DISTRIBUTION CODE

Unclassified - Unlimited

Subject Category 20

13. ABSTRACT (Maximum 200 words)

Capitalizing on past and future development of high temperature gas reactor (HTGR) technology, a low mass 15 MWe closed gas turbine cycle power system using a pellet bed reactor heating helium working fluid is proposed for Nuclear Electric Propulsion (NEP) applications. Although the design of this directly coupled system architecture, comprising the reactor/power system/space radiator subsystems, is presented in conceptual form, sufficient detail is included to permit an assessment of overall system performance and mass. Furthermore, an attempt is made to show how tailoring of the main subsystem design characteristics can be utilized to achieve synergistic system level advantages that can lead to improved reliability and enhanced system life while reducing the number of parasitic load driven peripheral subsytems. Other applications of this technology include power plants for lunar bases and planetary surface power generation installations of the future.

\begin{tabular}{|l|l|l|}
\hline $\begin{array}{c}\text { 14. SUBJECT TERMS } \\
\text { Space power system; Nuclear power; Nuclear electric propulsion }\end{array}$ \\
$\begin{array}{c}\text { 17. SECURITY CLASSIFICATION } \\
\text { OF REPORT } \\
\text { Unclassified }\end{array}$ & $\begin{array}{c}\text { 18. SECURITY CLASSIFICATION } \\
\text { OF THIS PAGE } \\
\text { Unclassified }\end{array}$ & $\begin{array}{c}\text { 19. SECURITY CLASSIFICATION } \\
\text { OF ABSTRACT } \\
\text { Unclassified }\end{array}$ \\
\hline
\end{tabular}


National Aeronautics and Space Administration

Lewis Research Center

Cleveland, Ohio 44135

Official Business

Penalty for Private Use $\$ 300$
FOURTH CLASS MAIL

ADDRESS CORRECTION REQUESTED

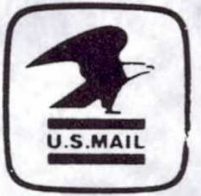

Postage and Fees Paid National Aeronautirs an

Space Administration NASA 451 